\title{
Molecular epidemiology of Staphylococcus aureus in African children from rural and urban communities with atopic dermatitis
}

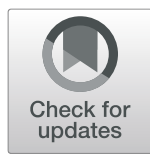

Gillian O. N. Ndhlovu', Regina E. Abotsi ${ }^{1,2,3}$, Adebayo O. Shittu ${ }^{4,5}$, Shima M. Abdulgader ${ }^{6}$, Dorota Jamrozy ${ }^{7}$, Christopher L. Dupont ${ }^{8}$, Avumile Mankahla ${ }^{9}$, Mark P. Nicol ${ }^{10}$, Carol Hlela ${ }^{11}$, Michael E. Levin ${ }^{11}$, Nonhlanhla Lunjani ${ }^{11}$ and Felix S. Dube ${ }^{1,2^{*}}$

\begin{abstract}
Background: Staphylococcus aureus has been associated with the exacerbation and severity of atopic dermatitis (AD). Studies have not investigated the colonisation dynamics of S. aureus lineages in African toddlers with AD. We determined the prevalence and population structure of $S$. aureus in toddlers with and without AD from rural and urban South African settings.

Methods: We conducted a study of AD-affected and non-atopic AmaXhosa toddlers from rural Umtata and urban Cape Town, South Africa. S. aureus was screened from skin and nasal specimens using established microbiological methods and clonal lineages were determined by spa typing. Logistic regression analyses were employed to assess risk factors associated with $\mathrm{S}$. aureus colonisation.

Results: S. aureus colonisation was higher in cases compared to controls independent of geographic location (54\% vs. $13 \%, p<0.001$ and $70 \%$ vs. $35 \%, p=0.005$ in Umtata [rural] and Cape Town [urban], respectively). Severe AD was associated with higher colonisation compared with moderate AD (86\% vs. 52\%, $p=0.015)$ among urban cases. Having AD was associated with colonisation in both rural (odds ratio [OR] 7.54, 95\% Cl 2.92-19.47) and urban (OR $4.2,95 \% \mathrm{Cl} 1.57-11.2)$ toddlers. In rural toddlers, living in an electrified house that uses gas (OR $4.08,95 \% \mathrm{Cl} 1.59-$ 10.44) or utilises kerosene and paraffin (OR 2.88, 95\% Cl 1.22-6.77) for heating and cooking were associated with increased S. aureus colonisation. However, exposure to farm animals (OR $0.3,95 \% \mathrm{Cl} 0.11-0.83$ ) as well as living in a house that uses wood and coal (OR $0.14,95 \% \mathrm{Cl} 0.04-0.49)$ or outdoor fire (OR 0.31, 95\% Cl 0.13-0.73) were protective. Spa types t174 and t1476, and t272 and t1476 were dominant among urban and rural cases, respectively, but no main spa type was observed among controls, independent of geographic location. In urban cases, spa type t002 and t442 isolates were only identified in severe AD, t174 was more frequent in moderate AD, and t1476 in severe AD.
\end{abstract}

Conclusion: The strain genotype of $\mathrm{S}$. aureus differed by AD phenotypes and rural-urban settings. Continued surveillance of colonising $S$. aureus lineages is key in understanding alterations in skin microbial composition associated with $\mathrm{AD}$ pathogenesis and exacerbation.

\footnotetext{
* Correspondence: fdube82@gmail.com

'Department of Molecular and Cell Biology, Faculty of Science, University of Cape Town, Cape Town, South Africa

Institute of Infectious Disease \& Molecular Medicine, University of Cape Town, Cape Town, South Africa

Full list of author information is available at the end of the article
}

(c) The Author(s). 2021 Open Access This article is licensed under a Creative Commons Attribution 4.0 International License, which permits use, sharing, adaptation, distribution and reproduction in any medium or format, as long as you give appropriate credit to the original author(s) and the source, provide a link to the Creative Commons licence, and indicate if changes were made. The images or other third party material in this article are included in the article's Creative Commons licence, unless indicated otherwise in a credit line to the material. If material is not included in the article's Creative Commons licence and your intended use is not permitted by statutory regulation or exceeds the permitted use, you will need to obtain permission directly from the copyright holder. To view a copy of this licence, visit http://creativecommons.org/licenses/by/4.0/ The Creative Commons Public Domain Dedication waiver (http://creativecommons.org/publicdomain/zero/1.0/) applies to the data made available in this article, unless otherwise stated in a credit line to the data. 


\section{Introduction}

Atopic dermatitis (AD) is a common childhood inflammatory skin disease that frequently presents in early childhood [1]. The prevalence of AD is high in developed countries where it affects $10-20 \%$ of children [2]. However, recent epidemiological data indicate an increase in the prevalence of AD among children in developing countries, including South Africa [3-5]. The increasing prevalence of $\mathrm{AD}$ and allergy is also associated with urbanisation with a lower prevalence and microbial-related protective environmental factors noted in rural areas $[3,6]$. Patients with AD usually suffer from persistent or relapsing itchy and dry eczematous skin lesions with inflammation and increased susceptibility to cutaneous Staphylococcus aureus (S. aureus) colonisation associated with perturbation of the skin microbial community $[7,8]$. In addition to skin colonisation, S. aureus has also been reported to colonise the nasal cavity as a primary reservoir for extra-nasal auto-transmission [9]. Skin and nasal $S$. aureus colonisation have been demonstrated in both $\mathrm{AD}$ patients and healthy individuals; however, a higher colonisation density and prevalence have been described in AD patients [9]. S. aureus colonisation has also been associated with $\mathrm{AD}$ pathogenesis [10], with colonisation preceding the clinical onset of AD in early childhood [11]. S. aureus produces a variety of virulence factors, including superantigens, proteases, as well as dermolytic and cytolytic toxins which contribute to the progression of $\mathrm{AD}$ [12]. Nonetheless, other staphylococcal species, including $S$. epidermidis and $S$. haemolyticus have been implicated in the pathophysiology of $\mathrm{AD}$ by the degradation of epidermal structural proteins $[13,14]$. Molecular epidemiological studies have shown that while colonisation occurs in both $\mathrm{AD}$ patients and healthy individuals, the genetic background of colonising S. aureus strains differ across AD disease phenotypes and may influence disease pathogenesis and severity $[1,15]$. We hypothesised that geographic location affects $S$. aureus colonisation in $\mathrm{AD}$ and health through distinct environmental exposures. Here, we report the prevalence and genotypes of $S$. aureus from skin and nasal samples of AmaXhosa AD and nonAD toddlers in rural and urban South African settings. In addition, we evaluated the risk factors for $S$. aureus colonisation in each geographic location.

\section{Materials and methods}

\section{Study design, setting and population Participant recruitment}

We conducted a cross-sectional study of 220 toddlers with and without AD aged 12-36 months (overall mean age 22.4 months; standard deviation 0.54 months) from February 2015 to May 2016 (Fig. 1) [6, 16]. Urban control subjects $(n=50)$ were recruited as a sub-study from non-allergic, non-food-sensitised subjects participating in the South African Food Allergy (SAFFA) study at randomly selected creches in the Cape Town metropole. As creches are rarely found in the rural district, rural controls $(n=54)$ were recruited from toddlers of eligible age from the areas surrounding 10 district community health clinics in the rural Mqanduli district of Umtata. Patients with moderate to severe $\mathrm{AD}(n=56)$ were recruited from

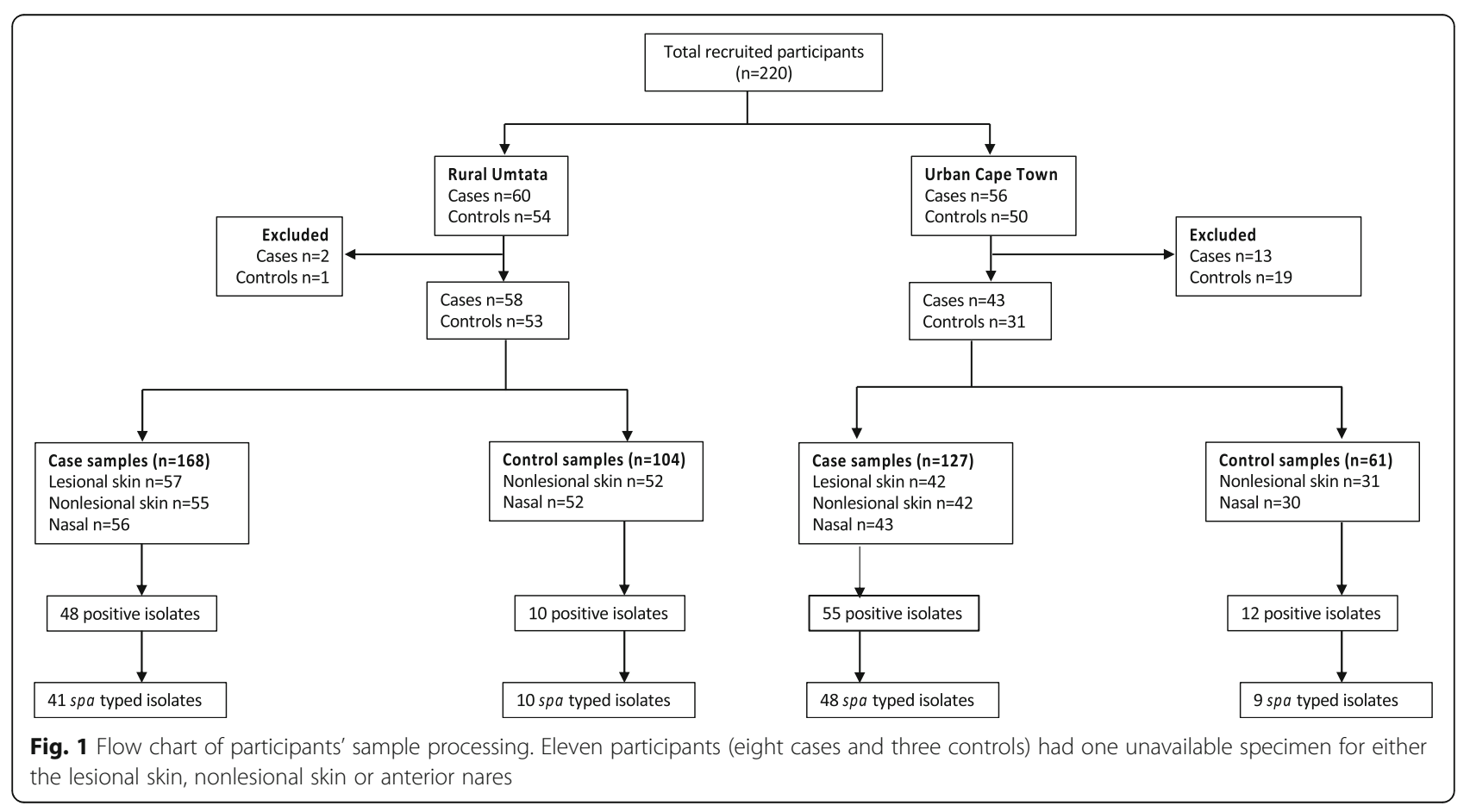


the Department of Paediatric Dermatology of the Red Cross War Memorial Children's Hospital in Cape Town and rural cases $(n=60)$ from the Department of Dermatology, Nelson Mandela Academic Hospital, in Umtata. $\mathrm{AD}$ was clinically diagnosed by a dermatologist using the validated UK Working Party diagnosis criteria for AD [17]. Disease severity was determined using the objective SCORAD (SCORing of Atopic Dermatitis) index into moderate (15-40) and severe (>40) [18]. Guardians completed a questionnaire aimed at determining environmental exposures as previously described [19].

\section{Specimen collection and processing}

Sterile Copan nylon-tipped flocked swabs (Cat. no. 516C; Copan Italia, Brescia, Italy) were used to collect samples from lesional (i.e., most active area of eczematous skin with acute and/or chronic changes) and nonlesional skin (i.e., area with the most normal-appearing skin - usually the back). The swab was pre-moistened with sterile distilled water and a $4 \mathrm{~cm}^{2}$ area of the skin lesion was swabbed for at least $1 \mathrm{~min}$ in a nonoverlapping manner. In addition, nasal swabs were collected from all participants to determine the $S$. aureus carriage status according to previously described methodology [20]. The collected swabs were immediately placed into $1 \mathrm{ml}$ skim milk-tryptone-glucose-glycerol (STGG), transported at $4{ }^{\circ} \mathrm{C}$ to the laboratory within two hours of collection and frozen at $-80^{\circ} \mathrm{C}$ for subsequent batch processing. All lesional, non-lesional, and nasal swabs stored in STGG were allowed to thaw at room temperature, vortexed for $30 \mathrm{~s}$ and $100 \mu \mathrm{l}$ was inoculated onto Mannitol Salt Agar (MSA) (National Health Laboratory Services [NHLS], Green Point Media Laboratory Cape Town, South Africa), and aerobically incubated at $37^{\circ} \mathrm{C}$ for $48 \mathrm{~h}$. Isolates that were positive for both mannitol fermentation and DNase production were presumptively identified as $S$. aureus [21].

\section{Nucleic acid extraction}

Recovered $S$. aureus isolates were aerobically subcultured onto $2 \%$ sheep blood agar at $37{ }^{\circ} \mathrm{C}$ overnight. Genomic DNA extraction was completed using a modified heat lysis method [22]. Briefly, colonies were resuspended in AVE buffer (Qiagen, Hilden, Germany) instead of phosphate-buffered saline and centrifuged at 13, $000 \mathrm{~g}$ for two minutes. The supernatant containing genomic DNA was diluted in AVE buffer depending on the initial DNA concentration to a final concentration range of $20-70 \mathrm{ng} / \mu \mathrm{l}$.

\section{Molecular identification of the S. aureus isolates}

Isolates presumptively identified as $S$. aureus were screened for the thermonuclease (nuc) gene using species-specific primers as previously described [23].

\section{Molecular characterisation}

S. aureus isolates were characterised by staphylococcus protein A (spa) typing targeting the variable X-region of the gene using the conventional primers spa-1113F/spa-1514R $[24,25]$. Isolates that failed to yield a spa amplicon or had poor sequence quality were re-analysed using alternative spa primers T3F/1517R or 1095F/1517R [26, 27]. Clustering was based on their genetic relatedness to spa-clonal complexes (spa-CCs) using the Based Upon Repeat Pattern (BURP) clustering algorithm of the Ridom Staph Type software (Ridom GmbH, Münster, Germany) [28]. PCR detection of the $n u c$ gene was performed to rule out misidentification of isolates that failed to yield a spa amplicon [23].

\section{Statistical analysis}

All data analyses were performed using Stata version SE16.0 (1985-2019 StataCorp LP, Texas, USA). The significance threshold for all analyses was 0.05 . Univariate and multivariate analyses to assess risk factors for $S$. aureus colonisation were performed using logistic regression and presented as odd ratios (OR) and adjusted ORs (aOR) reported with a 95\% confidence interval (CI). The level of statistical significance in the logistic regression analysis was determined by a Chi-square test. Variables that were significant determinants for colonisation were included in the multivariate logistic regression model. Comparison of categorical data was performed by Chisquared test unless stated otherwise. Comparison of means was performed using the $\mathrm{t}$-test for two independent samples reported with a standard deviation (SD). Participants with missing data were excluded from the analyses relating to that variable.

\section{Results}

\section{S. aureus colonisation in cases and controls}

A total of 185 (84 controls and 101 cases) toddlers were assessed for S. aureus colonisation (Table 1). Thirty-five participants were excluded (missing specimen) from the study analysis (Fig. 1). Of these, 79 (43\%) were colonised with $S$. aureus in at least one of the sampled body sites. There was an overall higher prevalence of colonisation among urban participants compared to rural participants (55\% [41/74] vs. $34 \%$ [38/111], $p=0.006)$. S. aureus was commonly detected from cases compared to controls in both rural $(54 \%[31 / 58]$ vs. $13 \%[7 / 53], p<0.001$ and urban settings $(70 \%$ [30/43] vs. $35 \%[11 / 31], p=0.005)$. Furthermore, cases were more frequently colonised on non-lesional skin compared to controls, and this was independent on geographic location (Additional file 1: Table S1). Among cases, colonisation was more common on lesional skin compared to non-lesional skin (rural: $p=0.035$ and urban: $p=0.021$ ) and the anterior nares (rural: $p=0.008$ ). The prevalence of colonisation was common among urban cases with severe disease $(86 \%$ 
Table 1 Participant characteristics of atopic dermatitis cases and healthy controls

\begin{tabular}{|c|c|c|c|c|c|c|c|c|}
\hline \multirow[t]{2}{*}{ Explanatory variable } & \multicolumn{4}{|l|}{ Umtata } & \multicolumn{4}{|l|}{ Cape Town } \\
\hline & Total, $n$ (\%) & Case, $n(\%)$ & Control, $n(\%)$ & $p$-value & Total, $n$ (\%) & Case, $n(\%)$ & Control, $n(\%)$ & $p$-value \\
\hline Total & $111(100)$ & $58(52)$ & $53(48)$ & $0.502^{\mathrm{a}}$ & 74 (100) & $43(58)$ & $31(42)$ & $0.049^{a}$ \\
\hline \multicolumn{9}{|l|}{ Age (months) } \\
\hline Mean [standard deviation] & $21.27[7.15]$ & $21.03[7.41]$ & $21.53[6.90]$ & 0.718 & $24.19[7.37]$ & $23.98[7.44]$ & $24.48[7.38]$ & 0.773 \\
\hline \multicolumn{9}{|l|}{ Sex } \\
\hline Female & $42(39)$ & $24(43)$ & $18(34)$ & 0.431 & $36(49)$ & $19(44)$ & $17(55)$ & 0.480 \\
\hline Male & $67(61)$ & $32(57)$ & $35(66)$ & & $38(51)$ & $24(56)$ & $14(45)$ & \\
\hline \multicolumn{9}{|l|}{$A D$ severity } \\
\hline Moderate & $23(40)$ & $23(40)$ & - & & $21(49)$ & $21(49)$ & - & \\
\hline Severe & $35(60)$ & $35(60)$ & - & & $22(51)$ & $22(51)$ & - & \\
\hline \multicolumn{9}{|l|}{ Atopic disease } \\
\hline Food allergy & $11(10)$ & $10(17)$ & $1(2)$ & 0.009 & $9(12)$ & $9(21)$ & $0(0)$ & 0.008 \\
\hline Asthma & $0(0)$ & $0(0)$ & $0(0)$ & & $1(1)$ & $1(3)$ & $0(0)$ & 1.000 \\
\hline Allergic rhinitis & 7 (8) & $1(2)$ & $6(11)$ & 0.242 & $1(1)$ & $1(3)$ & $0(0)$ & 1.000 \\
\hline \multicolumn{9}{|l|}{ Mode of birth } \\
\hline Caesarean section & $25(23)$ & $14(24)$ & $11(21)$ & 0.821 & $33(46)$ & $20(49)$ & $13(42)$ & 0.637 \\
\hline Vaginal & $86(77)$ & $44(76)$ & $42(79)$ & & $39(54)$ & $21(51)$ & $18(58)$ & \\
\hline Breastfeeding & $35(32)$ & $10(17)$ & $25(47)$ & 0.001 & $9(12)$ & $7(16)$ & $2(6)$ & 0.288 \\
\hline Antibiotic exposure & $92(82)$ & $49(83)$ & $43(81)$ & 0.810 & $54(72)$ & $30(70)$ & $24(77)$ & 0.598 \\
\hline \multicolumn{9}{|l|}{ Immunisation status } \\
\hline Complete & $107(96)$ & $56(95)$ & $52(98)$ & 0.620 & $64(86)$ & $33(77)$ & $31(100)$ & 0.004 \\
\hline Incomplete & $4(4)$ & $3(5)$ & $1(2)$ & & $10(14)$ & $10(23)$ & $0(0)$ & \\
\hline Large family $^{\mathrm{a}}$ & $62(55)$ & $30(52)$ & $32(60)$ & 0.445 & $24(32)$ & $14(33)$ & $10(32)$ & 1.000 \\
\hline Animal exposure & $93(84)$ & $39(67)$ & $53(100)$ & 0.001 & $2(3)$ & $2(6)$ & $0(0)$ & 0.495 \\
\hline \multicolumn{9}{|l|}{ Parental education } \\
\hline Primary & $8(7)$ & $2(3)$ & $6(11)$ & 0.001 & $1(1)$ & $1(2)$ & $0(0)$ & 0.025 \\
\hline Secondary & $70(63)$ & $31(53)$ & $39(74)$ & & $33(45)$ & $14(33)$ & $19(61)$ & \\
\hline Tertiary & $31(28)$ & $25(43)$ & $6(11)$ & & $40(54)$ & $28(65)$ & $12(39)$ & \\
\hline Other & $2(2)$ & $0(0)$ & $2(4)$ & & $0(0)$ & $0(0)$ & $0(0)$ & \\
\hline \multicolumn{9}{|l|}{ Maternal factors } \\
\hline Animal exposure & $96(86)$ & $44(76)$ & $52(98)$ & 0.001 & $4(60)$ & $4(11)$ & $0(0)$ & 0.120 \\
\hline Pregnant smoking & $1(1)$ & $0(0)$ & $1(2)$ & 0.482 & $3(45)$ & $0(0)$ & $3(10)$ & 0.094 \\
\hline Smoking & $1(1)$ & $0(0)$ & $1(2)$ & 0.477 & $4(6)$ & $1(3)$ & $3(10)$ & 0.324 \\
\hline Asthma & $2(2)$ & $2(3)$ & $0(0)$ & 0.496 & $6(8)$ & $4(10)$ & $2(6)$ & 1.000 \\
\hline Allergic rhinitis & $4(4)$ & $4(7)$ & $0(0)$ & 0.120 & $5(68)$ & $4(10)$ & $1(3)$ & 0.387 \\
\hline Atopic dermatitis & $2(2)$ & $2(3)$ & $0(0)$ & 0.496 & $3(4)$ & $2(5)$ & $1(3)$ & 1.000 \\
\hline Food allergy & $3(3)$ & $2(3)$ & $1(2)$ & 1.000 & $1(1)$ & $1(2)$ & $0(0)$ & 1.000 \\
\hline \multicolumn{9}{|l|}{ Paternal factors } \\
\hline Smoking & $15(14)$ & $9(16)$ & $6(12)$ & 0.589 & $20(31)$ & $11(31)$ & $9(31)$ & 1.000 \\
\hline Asthma & $3(3)$ & $3(5)$ & $0(0)$ & 0.245 & $0(0)$ & $0(0)$ & $0(0)$ & \\
\hline Allergic rhinitis & $3(3)$ & $3(5)$ & $0(0)$ & 0.245 & $7(10)$ & $7(17)$ & $0(0)$ & 0.018 \\
\hline Atopic dermatitis & $1(1)$ & $1(2)$ & $0(0)$ & 1.000 & $2(3)$ & $2(5)$ & $0(0)$ & 0.505 \\
\hline Food allergy & $1(1)$ & $1(2)$ & $0(0)$ & 1.000 & $1(1)$ & $1(2)$ & $0(0)$ & 1.000 \\
\hline
\end{tabular}


Table 1 Participant characteristics of atopic dermatitis cases and healthy controls (Continued)

\begin{tabular}{|c|c|c|c|c|c|c|c|c|}
\hline \multirow[t]{2}{*}{ Explanatory variable } & \multicolumn{4}{|l|}{ Umtata } & \multicolumn{4}{|l|}{ Cape Town } \\
\hline & Total, $n(\%)$ & Case, $\boldsymbol{n}(\%)$ & Control, $n$ (\%) & $\overline{p \text {-value }}$ & Total, $n(\%)$ & Case, $n$ (\%) & Control, $n$ (\%) & $\overline{p \text {-value }}$ \\
\hline Electricity + gas & $69(62)$ & $56(97)$ & $13(25)$ & 0.001 & $66(99)$ & $35(97)$ & $31(100)$ & 1.000 \\
\hline Kerosene + paraffin & $64(58)$ & $44(76)$ & $20(38)$ & 0.001 & $43(64)$ & $21(58)$ & $22(71)$ & 0.317 \\
\hline Paraffin & $38(34)$ & $6(10)$ & $32(60)$ & 0.001 & $0(0)$ & $0(0)$ & $0(0)$ & \\
\hline Indoor fire & $4(4)$ & $2(3)$ & $2(4)$ & 1.000 & $0(0)$ & $0(0)$ & $0(0)$ & \\
\hline Outdoor fire & $49(44)$ & $12(21)$ & $37(70)$ & 0.001 & $0(0)$ & $0(0)$ & $0(0)$ & \\
\hline Wood + fire & $31(28)$ & $4(7)$ & $27(51)$ & 0.001 & $0(0)$ & $0(0)$ & $0(0)$ & \\
\hline
\end{tabular}

Bold text indicates statistical significance. $A D$ atopic dermatitis, $C l$ confidence interval, IQR interquartile range; ${ }^{\text {a }}$ Large family is arbitrarily defined as 7 or more members living within one household

[19/22] vs. $52 \%[11 / 21], p=0.015)$, however, this was not associated with the site of colonisation (Additional file 2: Table S2). Overall, these findings show that geographic location influences the dynamics of $S$. aureus colonisation on skin and nares in $\mathrm{AD}$ and non-AD, and this is dependent on the site of colonisation and disease severity.

\section{Risk factors associated with $S$. aureus colonisation across the locations}

The effect of various risk factors on colonisation with $S$. aureus in toddlers from both locations using logistic regression are shown in Tables 2 and 3, for rural and urban toddlers, respectively. The univariate analysis models showed that having AD was associated with colonisation in both rural (OR 7.54, 95\% CI 22.92-19.47) and urban (OR 4.2, 95\% CI 1.57-11.2) toddlers. Also, living in an electrified house that utilises gas (OR 4.08, 95\% CI 1.59-10.44) and kerosene and paraffin (OR 2.88, 95\% CI 1.22-6.77) for heating and cooking were associated with an increased risk of $S$. aureus among the rural toddlers. Surprisingly, exposure to farm animals (OR 0.3, 95\% CI 0.11-0.83) as well as living in a house that uses wood and coal (OR 0.14, 95\% CI 0.04-0.49) and outdoor fire (OR 0.31, 95\% CI 0.13-0.73) were associated with lower odds of colonisation. In the multivariate model of rural toddlers, having $\mathrm{AD}$ (aOR 8.02, 95\% CI 1.2850.37) was retained as a risk factor for $S$. aureus colonisation, while living in a house that uses wood and coal for cooking and heating (aOR 0.02, 95\% CI 0.02-0.99) remained protective against $S$. aureus colonisation. No regression analysis was performed for urban toddlers because only $\mathrm{AD}$ showed an association with $S$. aureus. In summary, the findings highlight the importance of the immediate environment, or exposome, in $S$. aureus colonisation.

\section{Clonal lineages of recovered S. aureus isolates}

A total of 125 skin and nasal $S$. aureus isolates were recovered from cases and controls, however, only 108 isolates were characterised by spa typing (Fig. 1). Seventeen isolates were excluded from molecular analysis due to their failure to amplify the spa gene using the described primers or poor sequence quality for spa type assignment despite repeated sequencing. BURP analysis grouped 19 spa types into 6 spa-clonal complexes (spa$\mathrm{CCs}$ ) and $15 \mathrm{spa}$ types were singletons. Among toddlers with spa typed isolates, $25 \%(19 / 76)$ were colonised with one spa type, while 7\% (5/76) were colonised with different spa types on at least two of the sampled sites which were positive for $S$. aureus. One rural case toddler was colonised with spa type t062 on lesional skin and anterior nares, and with spa type t1399 on non-lesional skin which belongs to the same spa-CC. The most frequent spa types were spa-CC002/t002 (spa-CC/spa type; $8 \%$ ), spa cluster 4/t272 (9\%), spa cluster 6/t174 (14\%) and spa cluster 5/t1476 (18\%). Furthermore, we identified four new (t15783, t18354, t18750 and t19774) and one unassigned spa types (i.e., txAC).

\section{Distribution of $S$. aureus spa clonal lineages across locations by $A D$ disease and severity}

The rural and urban toddlers were colonised by different $S$. aureus spa clonal lineages. The spa cluster 4 was frequently identified among rural toddlers $(18 \%$ [9/51] vs. $4 \%$ [2/57], $p=0.015$ ) and spa cluster 6 in urban toddlers $(23 \%[13 / 57]$ vs. $6 \%[3 / 51], p=0.013)$ compared to their respective counterparts based on all sampled sites (Table 4). The diversity of spa types among cases was higher compared to controls in both locations (Fig. 2). Moreover, comparative analysis revealed that there was an overall significant difference in the distribution of spa clonal lineages between urban cases and controls $(p=$ 0.009 ), with spa cluster $5 /$ t1476 and spa cluster 6/t174 identified as predominant among cases. There was no overall difference between rural cases and controls $(p=$ 0.224 ), albeit, spa cluster 4/t272 and spa cluster 5/t1476 were the dominant spa clonal lineages among cases with no single most dominant spa clonal lineage among controls (Fig. 2). We also noted a significant difference in the distribution of spa clonal lineages among urban cases based on AD severity $(p=0.001)$. In these cases, 
Table 2 Unconditional logistic regression analysis of child, parental, domestic and environmental characteristics associated with S. aureus colonisation in Umtata participants

\begin{tabular}{|c|c|c|c|c|c|c|}
\hline Explanatory variable & Colonised $^{\mathrm{a}}, n(\%)$ & Not colonised, $n(\%)$ & OR $[95 \% \mathrm{Cl}]$ & $p$-value & aOR $[95 \% \mathrm{Cl}]$ & $p$-value \\
\hline AD: case & $31(28)$ & $27(24)$ & $7.54[2.92-19.47]$ & 0.000 & $8.02[1.28-50.37]$ & 0.026 \\
\hline Sex: male & $21(19)$ & $46(42)$ & $0.74[0.33-1.67]$ & 0.469 & $0.83[0.32-2.16]$ & 0.696 \\
\hline \multicolumn{7}{|l|}{ Child characteristics } \\
\hline Breastfeeding & $10(9)$ & $25(23)$ & $0.69[0.29-1.63]$ & 0.395 & $1.46[0.48-4.47]$ & 0.503 \\
\hline Allergic rhinitis & $1(1)$ & $6(7)$ & $0.43[0.05-3.79]$ & 0.449 & Excluded & \\
\hline Asthma $^{\S}$ & $0(0)$ & $0(0)$ & Omitted $^{d}$ & & Excluded & \\
\hline Food allergy & $5(5)$ & $6(5)$ & $1.69[0.48-5.95]$ & 0.413 & Excluded & \\
\hline Mode of delivery: vaginal & $29(26)$ & $57(51)$ & $0.9[0.36-2.29]$ & 0.833 & Excluded & \\
\hline Incomplete immunisation status & $2(2)$ & $2(2)$ & $1.97[0.27-14.58]$ & 0.506 & Excluded & \\
\hline Antibiotic exposure & $33(30)$ & $58(52)$ & $1.71[0.57-5.12]$ & 0.34 & $1.54[0.39-6]$ & 0.536 \\
\hline Large family size ${ }^{b}$ & $15(14)$ & $35(32)$ & $0.71[0.32-1.57]$ & 0.395 & $0.94[0.36-2.44]$ & 0.903 \\
\hline Animal exposure ${ }^{c}$ & $27(24)$ & $65(59)$ & $0.3[0.11-0.83]$ & 0.021 & $0.53[0.11-2.54]$ & 0.429 \\
\hline \multicolumn{7}{|l|}{ Fossil fuel exposure } \\
\hline Electricity + gas & $31(28)$ & $38(34)$ & 4.08 [1.59-10.44] & 0.003 & $0.35[0.05-2.47]$ & 0.295 \\
\hline Kerosene + paraffin & $28(25)$ & $36(32)$ & 2.88 [1.22-6.77] & 0.015 & 0.69 [0.19-2.49] & 0.571 \\
\hline Indoor fire & $1(1)$ & $3(3)$ & $0.63[0.06-6.27]$ & 0.694 & Excluded & \\
\hline Outdoor fire & $10(9)$ & $39(35)$ & $0.31[0.13-0.73]$ & 0.008 & $0.54[0.17-1.67]$ & 0.283 \\
\hline Wood + coal & $3(3)$ & $28(25)$ & $0.14[0.04-0.49]$ & 0.002 & $0.14[0.02-0.99]$ & 0.048 \\
\hline \multicolumn{7}{|l|}{ Maternal factors } \\
\hline Allergic rhinitis & $0(0)$ & $4(4)$ & Omitted $^{d}$ & & Excluded & \\
\hline Asthma & $1(1)$ & $1(1)$ & $1.95[0.12-32]$ & 0.641 & Excluded & \\
\hline Atopic dermatitis & $1(1)$ & $1(1)$ & $1.95[0.12-32]$ & 0.641 & Excluded & \\
\hline Food allergy & $1(1)$ & $2(2)$ & $0.96[0.08-10.93]$ & 0.973 & Excluded & \\
\hline Smoking & $0(0)$ & $1(1)$ & Omitted & & Excluded & \\
\hline Pregnant smoker & $0(0)$ & $1(1)$ & Omitted & & Excluded & \\
\hline Animal exposure ${ }^{c}$ & $31(28)$ & $65(59)$ & $0.55[0.18-1.64]$ & 0.28 & $1.93[0.37-10.16]$ & 0.438 \\
\hline \multicolumn{7}{|l|}{ Paternal factors } \\
\hline Allergic rhinitis ${ }^{\S}$ & $0(0)$ & $3(3)$ & Omitted & & Excluded & \\
\hline Asthma ${ }^{\S}$ & $1(1)$ & $2(2)$ & $0.96[0.08-10.93]$ & 0.973 & Excluded & \\
\hline Atopic dermatitis ${ }^{\S}$ & $0(0)$ & $1(1)$ & Omitted & & Excluded & \\
\hline Food allergy ${ }^{\S}$ & $0(0)$ & $1(1)$ & Omitted & & Excluded & \\
\hline Smoking & $5(5)$ & $10(9)$ & $0.94[0.3-2.98]$ & 0.267 & Excluded & \\
\hline
\end{tabular}

$A D$ atopic dermatitis, $O R$ odds ratio, $a O R$ adjusted odds ratio, $\mathrm{Cl}$ confidence interval; ${ }^{\S}$ No within group variance; ${ }^{\mathrm{a}}$ Colonisation with Staphylococcus aureus; ${ }^{\mathrm{b}}$ Large family size is arbitrarily defined as 7 or more members within a household; ${ }^{c}$ Animal exposure refers to farm animals; ${ }^{d}$ Independent variables omitted due to dependency in the regression model

spa-CC002 (t002 and t442) isolates were only identified in severe AD, spa cluster 6/t174 was more frequent in moderate $\mathrm{AD}$, and spa cluster 5/ t1476 in severe AD. Although no significant difference was observed between AD severity and the identified spa types in rural cases $(p=0.126)$, spa cluster 3 (t062 and t1399) isolates were only detected in moderate cases while spa cluster 5 (t1476 and t1257) isolates predominated in severe cases (Fig. 3).

\section{Discussion}

We conducted a cross-sectional, case-control study to determine the molecular epidemiology of $S$. aureus colonising the skin and nasal cavity of $\mathrm{AD}$-affected and healthy South African AmaXhosa toddlers. We observed a higher prevalence of colonisation in cases compared to controls, regardless of geographic location. The distribution of $S$. aureus spa clonal lineages differed between rural-urban settings and differentially associated with $\mathrm{AD}$ disease and severity. Moreover, determinants of $S$. 
Table 3 Unconditional logistic regression analysis of child, parental, domestic and environmental characteristics associated with S. aureus colonisation in Cape Town participants

\begin{tabular}{|c|c|c|c|c|}
\hline Explanatory variable & Colonised $^{\mathrm{a}}, n(\%)$ & Not colonised, $n(\%)$ & OR $[95 \% \mathrm{Cl}]$ & $p$-value \\
\hline AD: case & $30(41)$ & $13(18)$ & $4.2[1.57-11.2]$ & 0.004 \\
\hline Sex: male & $19(26)$ & $19(25)$ & $0.74[0.33-1.67]$ & 0.469 \\
\hline \multicolumn{5}{|l|}{ Child characteristics } \\
\hline Breastfeeding & $6(8)$ & $3(4)$ & $1.71[0.39-7.45]$ & 0.472 \\
\hline \multicolumn{5}{|l|}{ Atopic dermatitis } \\
\hline Allergic rhinitis & $1(1)$ & $0(0)$ & Omitted $^{d}$ & \\
\hline Asthma $^{\S}$ & $1(1)$ & $0(0)$ & Omitted $^{d}$ & \\
\hline Food allergy & $6(8)$ & $3(4)$ & $1.71[0.39-7.45]$ & 0.472 \\
\hline Mode of delivery: vaginal & $22(31)$ & $17(24)$ & $0.95[0.37-2.43]$ & 0.921 \\
\hline Incomplete immunisation status & $8(11)$ & $2(3)$ & $3.76[0.74-19.09]$ & 0.11 \\
\hline Antibiotic exposure & $31(42)$ & $23(31)$ & $1.35[0.48-3.77]$ & 0.57 \\
\hline Large family size ${ }^{b}$ & $9(12)$ & $8(11)$ & $0.88[0.3-2.61]$ & 0.816 \\
\hline Animal exposure ${ }^{c}$ & $1(1)$ & $1(1)$ & $0.86[0.05-14.3]$ & 0.915 \\
\hline \multicolumn{5}{|l|}{ Fossil fuel exposure } \\
\hline Electricity + gas & $36(54)$ & $30(45)$ & Omitted $^{d}$ & \\
\hline Kerosene + paraffin & $20(30)$ & $23(34)$ & $0.43[0.15-1.23]$ & 0.116 \\
\hline Indoor fire & $0(0)$ & $0(0)$ & Omitted $^{d}$ & \\
\hline Outdoor fire & $0(0)$ & $0(0)$ & Omitted $^{d}$ & \\
\hline Wood + coal & $0(0)$ & $0(0)$ & Omitted $^{d}$ & \\
\hline \multicolumn{5}{|l|}{ Maternal factors } \\
\hline Allergic rhinitis & $0(0)$ & $5(7)$ & Omitted ${ }^{d}$ & \\
\hline Asthma & $3(4)$ & $3(4)$ & $0.76[0.14-4.06]$ & 0.751 \\
\hline Atopic dermatitis & $1(1)$ & $2(3)$ & $0.38[0.03-4.33]$ & 0.432 \\
\hline Food allergy & $1 / 73$ & $0(0)$ & Omitted $^{d}$ & \\
\hline Smoking & $3(4)$ & $1(1)$ & $2.65[0.26-26.82]$ & 0.41 \\
\hline Pregnant smoker & $2(3)$ & $1(1)$ & $1.76[0.15-20.45]$ & 0.65 \\
\hline Animal exposure ${ }^{c}$ & $3(5)$ & $1(2)$ & $2.64[0.26-26.76]$ & 0.412 \\
\hline \multicolumn{5}{|l|}{ Paternal factors } \\
\hline Allergic rhinitis ${ }^{\S}$ & $5(7)$ & $2(3)$ & $2.08[0.38-11.52]$ & 0.4 \\
\hline Asthma $^{\S}$ & $0(0)$ & $0(0)$ & Omitted $^{d}$ & \\
\hline Atopic dermatitis ${ }^{\S}$ & $2(3)$ & $0(0)$ & Omitted $^{d}$ & \\
\hline Food allergy ${ }^{\S}$ & $1(1)$ & $0(0)$ & Omitted $^{d}$ & \\
\hline Smoking & $13(20)$ & $7(11)$ & $1.86[0.62-5.54]$ & 0.267 \\
\hline
\end{tabular}

aureus colonisation varied across the rural-urban settings.

The pathogenesis of $\mathrm{AD}$ is characterised by epidermal barrier defects and activation of inflammatory responses leading to impaired clearance of skin pathogens and a decrease in skin microbial diversity [10]. S. aureus dominance is consistently linked with acute AD flares and severe forms of the disease [29, 30]. We noted a higher prevalence of $S$. aureus colonisation among cases compared to controls which was independent of geographic location (55\% vs. 13 and $70 \%$ vs. $35 \%$ in rural and urban locations, respectively). These findings are consistent with a similar study in Italy that reported a prevalence of $57 \%$ vs. $20 \%$ in cases compared to controls [31]. Therefore, these findings support the relationship between $S$. aureus predominance and $\mathrm{AD}$, regardless of population and location $[9,31]$. 
Table 4 Distribution of clonal lineages of S. aureus isolates among Umtata and Cape Town participants

\begin{tabular}{|c|c|c|c|c|c|c|}
\hline \multirow[t]{2}{*}{ spa-CC } & \multicolumn{3}{|l|}{ Umtata } & \multicolumn{3}{|c|}{ Cape Town } \\
\hline & $\begin{array}{l}\text { No. of } \\
\text { isolates } \\
\text { (\%) }\end{array}$ & $\begin{array}{l}\text { No. of } s p a \\
\text { types (\%) }\end{array}$ & spa types (no. of isolates) & $\begin{array}{l}\text { No. of } \\
\text { isolates } \\
\text { (\%) }\end{array}$ & $\begin{array}{l}\text { No. of } \\
\text { spa types } \\
\text { (\%) }\end{array}$ & spa types (no. of isolates) \\
\hline spa-CCO02 & 9 & $3(14)$ & t002 (4); t045 (2); t071 (3) & 10 & $4(19)$ & $\begin{array}{l}\text { t002 (5); t1215 (2); t18748 (1); } \\
\text { t442 (2) }\end{array}$ \\
\hline spa-CC084 & 3 & $2(10)$ & t084 (2); t491 (1); t19774 (1) & 5 & $2(10)$ & t084 (3); t346 (2) \\
\hline spa cluster 3 & 3 & $2(10)$ & t062 (2); t1399 (1) & 3 & $2(10)$ & t062 (1); t2049 (2) \\
\hline spa cluster 4 & 9 & $2(10)$ & t159 (1); t272 (8) & 2 & $1(5)$ & t272 (2) \\
\hline spa cluster 5 & 12 & $2(10)$ & t1476 (10); t1257 (2) & 10 & $2(10)$ & t1476 (9); t18750 (1) \\
\hline spa cluster 6 & 3 & $1(5)$ & t174 (3) & 13 & $2(10)$ & t174 (12); t5471 (1) \\
\hline Singletons & 10 & $7(33)$ & $\begin{array}{l}\text { t015 (2); t148 (1); t2763 (1); } \\
\text { t317 (3); t355 (1); t786 (1); t843 } \\
\text { (1) }\end{array}$ & 13 & $7(33)$ & $\begin{array}{l}\text { t015 (2); t18354 (1); t1597 (1); } \\
\text { t2078 (4); t335 (2); t881 (1); t891 } \\
\text { (2) }\end{array}$ \\
\hline $\begin{array}{l}\text { Unaligned/spa types with } \\
\text { unknown repeat succession }\end{array}$ & 2 & $2(10)$ & $\operatorname{txAC}(1)$ & 1 & $1(5)$ & t15783 (1) \\
\hline Total & 51 & 21 & & 57 & 21 & \\
\hline
\end{tabular}

Bold text indicates spa types that were identified in only one location

AD-lesional skin has been shown to be more susceptible to $S$. aureus colonisation compared to ADuninvolved, non-lesional skin, with a reported prevalence of colonisation of $23-70 \%$ vs. $6-39 \%$ [9, 32, 33]. Similarly, we noted a higher frequency of colonisation on lesional skin compared to non-lesional skin among urban and rural cases. Furthermore, similar colonisation rates on lesional skin and anterior nares have been reported in $\mathrm{AD}$, with $S$. aureus nasal colonisation suggested as the main source of the increased skin colonisation in $\mathrm{AD}[9,34]$. However, we observed that lesional skin was more frequently colonised compared to the anterior nares among rural cases, suggesting a nonnasal source of $S$. aureus for the increased colonisation on lesional skin in rural $\mathrm{AD}$ or transient nasal colonisation $[31,35]$.

Skin barrier dysfunction in AD lesions, particularly in severe $\mathrm{AD}$, has been correlated with increased $S$. aureus colonisation [36, 37]. In agreement with recent studies $[9,33,37]$, we noted a higher prevalence of colonisation
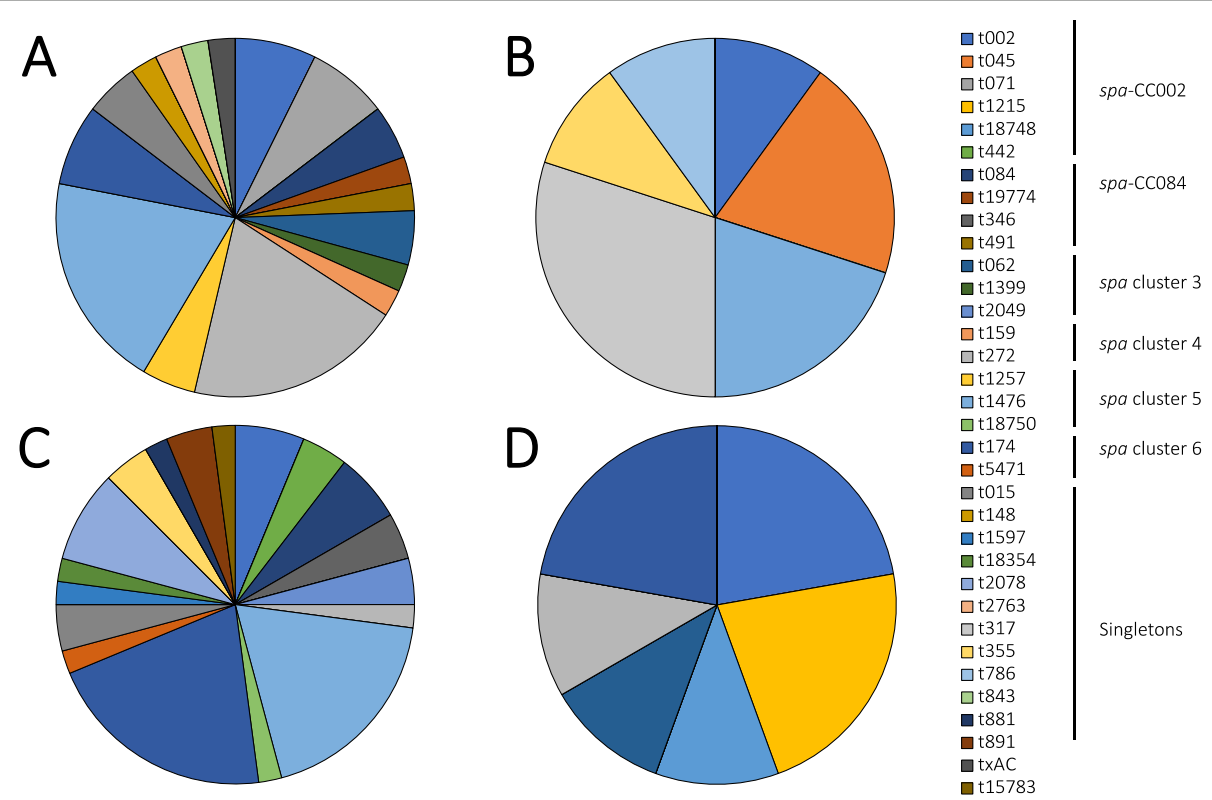

Fig. 2 Distribution of spa types by disease phenotype stratified by location. a rural case, (b) rural control, (c) urban case, and (d) urban control. Percentages were calculated by the number of isolates for a spa type divided by the total number of spa types in each group 

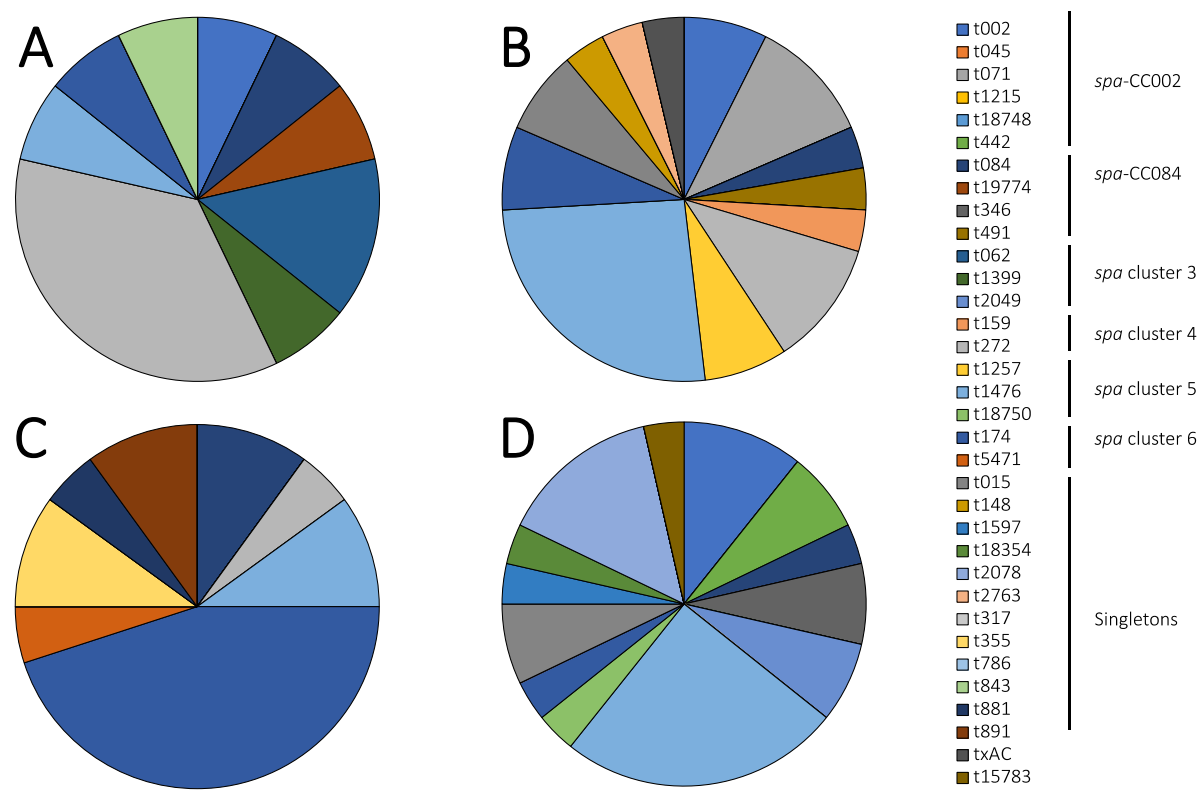

Fig. 3 Distribution of spa types by disease severity. a rural moderate, (b) rural severe, (c) urban moderate, and (d) urban severe. Percentages were calculated by the number of isolates for a spa type divided by the total number of spa types in each group

based on all sampled sites in cases with severe AD, however, this was limited to urban cases and not rural cases. Geographical location has been postulated to influence microbial colonisation and may explain the varied susceptibility of geographical populations to skin pathologies [38]. In this regard, the study communities each represent a geographic population that is uniquely affected by $S$. aureus colonisation in the pathophysiology of AD. Moreover, the rural and urban populations, regardless of disease, are generally different populations with distinct sensitisation patterns to environmental exposures [16] and inflammatory immune responses [39]. These may in turn affect microbial colonisation and the contribution thereof to disease pathogenesis and pathophysiology.

Risk factors for bacterial colonisation on the skin and nasal cavity differ with rural-urban living [40, 41]. The association between $S$. aureus colonisation and $\mathrm{AD}$ is well studied, with some studies reporting colonisation preceding the onset of clinically appreciable AD in toddlers and further associated with disease severity [11]. Consistent with previous reports [30], having AD in both communities was associated with $S$. aureus colonisation. Exposure to air pollutants has also been associated with increased skin barrier damage [42] which increases the propensity to $S$. aureus colonisation [43]. In rural toddlers, we observed that living in a house that uses kerosene and paraffin which release fine air particulates [44] was associated with increased $S$. aureus colonisation. However, exposure to the burning of wood/coal or outdoor fire, which also release fine air pollutants that may induce cutaneous irritation was associated with reduced S. aureus colonisation in rural toddlers. The effect of environmental air pollutants in children is a function of exposure time [45]. Although the toddlers are living in homes that use wood/coal or an outdoor fire for cooking and heating, they might have limited exposure to the produced particulates which restrict the possible effect on skin irritation and susceptibility to $S$. aureus. Electricity and biogas are relatively "clean fuels" with minimal air pollution emission at the household level [46]. In contrast, we found that rural living in an electrified house that also utilises gas increased the risk of $S$. aureus colonisation. Animals are reservoirs for human S. aureus colonisation [47], however, we found that rural toddlers living in a house with farm animals were associated with a reduced risk of $S$. aureus colonisation. Similarly, this finding could be due to the absence of direct interaction between toddlers and animals hence there are no animal-to-human $S$. aureus transmission events. Nonetheless, $\mathrm{AD}$ remained a risk factor while living in a house that uses wood and coal was protective against $S$. aureus colonisation in rural toddlers in the multivariate regression model. These findings highlight the importance of the immediate environment in shaping bacterial colonisation dynamics and the potential implication thereof in $\mathrm{AD}$ pathogenesis.

In addition to microbial colonisation, geographic location also determined the genotype of the colonising bacteria [48]. We noted heterogeneity in the distribution of the colonising spa clonal lineages based on geographic location, with rural toddlers mostly colonised by spa 
types belonging to the spa cluster 4 (previously associated with MLST CC121, Table S1) [49] while urban toddlers were predominantly colonised with spa cluster 6 (CC1) isolates [50]. This is similar to studies that suggest that location may play a role in the colonisation dynamics of childhood skin and nares [1, 15, 51, 52]. Furthermore, urban cases and controls exhibited distinct $S$. aureus spa clonal lineages, however, there was no difference in the distribution of $S$. aureus lineages between rural cases and controls. These findings suggest that the rural-urban locations provide a specific niche for the selection of certain S. aureus clonal lineages which sequentially influence the population structure in these settings, and associated colonisation dynamics. Future studies are essential to investigate site-specific features in this cohort that contribute to the observed $S$. aureus population structures and their association with disease phenotype.

The relationship between disease severity and the clonal lineages of the colonising $S$. aureus isolates is unclear with some studies reporting an association between specific clonal lineages and $\mathrm{AD}$ severity $[15,51]$ and others demonstrating none [34, 53]. In spite of this, we noted different distributions of $S$. aureus clonal lineages depending on AD severity among urban cases. Here, spa clonal lineages spa cluster 5 (CC5) [54] and spa cluster 6 (CC1) [50] were the most common in severe and moderate $\mathrm{AD}$, respectively. The spa-CC002 (CC5) [15] isolates were only detected in severe AD cases. These findings are in agreement with a study in Spanish children which reported a predominance of $\mathrm{CC} 5$ isolates in severe $\mathrm{AD}$ [51] and another on the predominance of $\mathrm{CC} 1$ isolates in moderate $\mathrm{AD}$ [34], but in contrast to a report of the predominance of CC5 in moderate disease among Canadian children with $\mathrm{AD}$ [15]. There was a difference in the distribution of spa clonal lineages among rural cases based on disease severity. Albeit, spa cluster 3 (CC5) $[49,55]$ isolates were only identified in rural cases with moderate $\mathrm{AD}$ and spa cluster 6 (CC1) [50] isolates were frequent in rural cases with severe AD. The predominance of spa cluster 3 (CC5) isolates is similar to that noted in moderate $\mathrm{AD}$ elsewhere [15] while that of spa cluster 6 (CC1) isolates in severe $\mathrm{AD}$ is in contrast to previous reports of the high prevalence of $\mathrm{CC} 1$ isolates in children with moderate AD [34]. The contrasting predominance of $S$. aureus clonal lineages based on disease severity across the rural-urban communities emphasises the importance of the environment in the contribution of bacterial clonality in disease. Therefore, more investigations are needed to determine if certain $S$. aureus clonal lineages are associated with differential AD disease severity and the concomitant contribution to $\mathrm{AD}$ and disease severity.
Our data are subject to a few limitations. BURP analyses are limited to spa types with a cut-off $\leq 5$ repeats, which excludes spa types with the number of repeats below the set parameter [28]. Therefore, spa type t15783 was excluded from BURP clustering analyses. Secondly, we predicted the corresponding MLST sequence types (STs) and CCs of the S. aureus spa types identified in this study by extrapolating data from previous studies (Additional file 3: Table S3). Furthermore, 14\% (17/125) of the isolates were untypeable which highlights the need for whole-genome sequencing (WGS) to provide both spa and MLST data for detailed characterisation [1].

\section{Conclusion}

Our study shows that toddlers with AD are more frequently colonised with $S$. aureus compared to non-AD controls. The genetic background of colonising S. aureus is a unique signature of $\mathrm{AD}$ and disease severity, however, this is largely dependent on rural-urban living. These findings highlight the importance of geographic location on the colonisation epidemiology and population structure of $S$. aureus as well as the associated colonisation determinants in childhood health and AD disease in South Africa. Future studies are planned to examine the mechanisms within the rural-urban environments that contribute to $S$. aureus colonisation dynamics and the association thereof with $\mathrm{AD}$ and disease severity. This information will provide insights into population-specific therapeutic strategies that may be harnessed in the restoration of microbial diversity in AD-affected toddlers.

\section{Abbreviations}

AD: Atopic dermatitis; BURP: Based Upon Repeat Pattern; CC: Clonal complex; $\mathrm{Cl}$ : Confidence interval; MLST: Multi-locus sequence typing;

nuc: Thermonuclease; OR: Odds ratio; aOR: Adjusted odds ratio; STGG: Skim milk-tryptone-glucose-glycerol; SD: Standard deviation; SAFFA: South African Food Allergy study; SCORAD: Scoring of atopic dermatitis;

Spa: Staphylococcus protein A; Spa-CC: Spa clonal cluster; ST: Sequence type

\section{Supplementary Information}

The online version contains supplementary material available at https://doi. org/10.1186/s12879-021-06044-4.

Additional file 1: Table S1. Participant colonisation among all, rural and urban cases and controls. This table is showing the distribution of $S$. aureus colonisation in $\mathrm{AD}$ and non-AD toddlers in the rural and urban locations.

Additional file 2: Table S2. Colonisation in cases stratified by disease severity among all, rural and urban cases. This table is showing the distribution of $S$. aureus colonisation based on disease severity in $A D$ toddlers in the rural and urban locations.

Additional file 3: Table S3. Extrapolated MLST sequence types and clonal complexes for spa types identified in the present study. This table is correlating the spa types identified in this study to MLST clonal complexes and sequence types reported in previous studies.

\section{Acknowledgements}

We would like to acknowledge the SOSALL study participants and families and research team. We would also like to thank Division of Medical 
Microbiology staff, particularly Charmaine Barthus and members of Dube Lab for their help and technical assistance. We thank Anne von Gottberg, Linda de Gouveia and the staff of the Centre for Respiratory Diseases and Meningitis (CRDM), National Institute for Communicable Diseases (NICD) of the National Health Laboratory Service for training, sharing of standard operating procedures, supplying control isolates. The abstract of this study was published as part of the International Congress on Infectious Diseases 2020 conference and is available online at https://doi.org/10.1016/j.ijid.2020. 09.1083 .

\section{Supporting information}

Supplementary results on S. aureus colonisation based on AD and health, $S$. aureus colonisation based on disease severity, study spa types and MLST sequence types are available as additional files on the Journal's website.

\section{Authors' contributions}

FSD, MEL, CH, NL, MPN, SMA, REA, CLD and AOS conceptualised and supervised this study. FSD, NL, CH and MEL obtained funding. NL and AM collected all clinical specimens. GONN, FSD, SMA and REA performed the experiments, data collection and analysis with support from DJ and AOS. GONN and FSD prepared the first draft manuscript. All authors contributed to manuscript review. The author(s) read and approved the final manuscript.

\section{Funding}

We acknowledge the Medical Research Council of South Africa, Nestlé Foundation, Mylan, Thermo Fisher Scientific funding of the parent study, and the Allergy Society of South Africa (ALLSA) for funding of this study. GONN acknowledges the National Research Foundation and the University of Cape Town Vice Chancellor's Research Scholarship for their financial assistance towards her MSc degree. REA is currently an Organisation of Women in Science for the Developing World (OWSD) and L'OREAL-UNESCO Women in Science PhD Fellow. She also acknowledges the financial support of the Swedish International Development Cooperation Agency (Sida) and Margaret McNamara Education Grants. SMA holds the Claude Leon Postdoctoral Research Fellowship. AOS is currently an awardee of the Georg Forster Research Fellowship (for Experienced Researchers) of the Alexander von Humboldt Foundation. FSD is supported by the National Research Foundation of South Africa (112160), Future Leaders - African Independent Research (FLAIR) Fellowship, NIHR-MPRU, the University of Cape Town and the Allergy Society of South Africa (ALLSA).

\section{Availability of data and materials}

The datasets used and analysed during the current study are available from the corresponding author on reasonable request and ethical approval.

\section{Declarations}

\section{Ethics approval and consent to participate}

The study was approved by the Human Research and Ethics Committee of the Faculty of Health Science, University of Cape Town (HREC/REF: 451/2014) and the Western Cape Provincial Child Health Research Committee. No additional data was collected other than that approved in the parent study. Written informed consent and assent were given by guardians and participants, respectively. All data obtained and generated during the study were kept confidential. This research was conducted in accordance with the Declaration of Helsinki.

\section{Consent for publication}

Not applicable.

\section{Competing interests}

Adebayo Shittu and Mark Nicol are members of the editorial board for the BMC Infectious Diseases journal.

\section{Author details}

'Department of Molecular and Cell Biology, Faculty of Science, University of Cape Town, Cape Town, South Africa. Institute of Infectious Disease \& Molecular Medicine, University of Cape Town, Cape Town, South Africa. ${ }^{3}$ Department of Pharmaceutical Microbiology, School of Pharmacy, University of Health and Allied Sciences, Ho, Ghana. ${ }^{4}$ Department of Microbiology, Obafemi Awolowo University, Ile-Ife, Osun State, Nigeria. Institute of Medical
Microbiology, University Hospital Münster, Münster, West Germany. ${ }^{6}$ Department of Pathology, Division of Medical Microbiology, Faculty of Medicine and Health Sciences, Stellenbosch University, Tygerberg, South Africa. ${ }^{7}$ Parasites and Microbes Programme, Wellcome Sanger Institute, Hinxton, UK. ${ }^{8}$ J. Craig Venter Institute, La Jolla, California, USA. ${ }^{9}$ Department of Medicine and Pharmacology, Division of Dermatology, Walter Sisulu University, Umtata, South Africa. ${ }^{10}$ Division of Infection and Immunity, School of Biomedical Sciences, University of Western Australia, Perth, Australia.

${ }^{11}$ Department of Paediatrics, Division of Paediatric Allergy, University of Cape Town, Cape Town, South Africa.

Received: 20 October 2020 Accepted: 5 April 2021

Published online: 13 April 2021

\section{References}

1. Harkins CP, Pettigrew KA, Oravcova K, et al. The microevolution and epidemiology of Staphylococcus aureus colonization during atopic eczema disease flare. J Invest Dermatol. 2018;138(2):336-43. https://doi.org/10.1016/j. jid.2017.09.023.

2. Gur Cetinkaya P, Sahiner UM. Childhood atopic dermatitis: current developments, treatment approaches, and future expectations. Turk J Med Sci. 2019;49(4):963-84. https://doi.org/10.3906/sag-1810-105.

3. Nutten S. Atopic dermatitis: global epidemiology and risk factors. Ann Nutr Metab. 2015;66(Suppl 1):8-16. https://doi.org/10.1159/000370220.

4. Williams H, Stewart A, von Mutius E, Cookson W, Anderson HR. Is eczema really on the increase worldwide? J Allergy Clin Immunol. 2008;121(4):94754 e915. https://doi.org/10.1016/j.jaci.2007.11.004.

5. Civelek E, Sahiner UM, Yuksel H, et al. Prevalence, burden, and risk factors of atopic eczema in schoolchildren aged 10-11 years: a national multicenter study. J Investig Allergol Clin Immunol. 2011;21(4):270-7.

6. Levin ME, Botha M, Basera W, Facey-Thomas HE, Gaunt B, Gray CL, et al. Environmental factors associated with allergy in urban and rural children from the south African food allergy (SAFFA) cohort. J Allergy Clin Immunol. 2020;145(1):415-26. https://doi.org/10.1016/j.jaci.2019.07.048.

7. Eyerich $\mathrm{K}$, Eyerich S, Biedermann $\mathrm{T}$. The multi-modal immune pathogenesis of atopic eczema. Trends Immunol. 2015;36(12):788-801. https://doi.org/10.1 016/j.it.2015.10.006.

8. Mernelius S, Carlsson E, Henricson J, Löfgren S, Lindgren PE, Ehricht R, et al. Staphylococcus aureus colonization related to severity of hand eczema. Eur J Clin Microbiol Infect Dis. 2016;35(8):1355-61. https://doi.org/10.1007/s1 0096-016-2672-2.

9. Totte JE, van der Feltz WT, Hennekam M, van Belkum A, van Zuuren EJ, Pasmans SG. Prevalence and odds of Staphylococcus aureus carriage in atopic dermatitis: a systematic review and meta-analysis. Br J Dermatol. 2016;175(4):687-95. https://doi.org/10.1111/bjd.14566.

10. Magnifico I, Petronio Petronio G, Venditti N, et al. Atopic Dermatitis as a Multifactorial Skin Disorder. Can the Analysis of Pathophysiological Targets Represent the Winning Therapeutic Strategy? Pharmaceuticals (Basel). 2020; 13(11).

11. Meylan P, Lang C, Mermoud S, Johannsen A, Norrenberg S, Hohl D, et al. Skin colonization by Staphylococcus aureus precedes the clinical diagnosis of atopic dermatitis in infancy. J Invest Dermatol. 2017;137(12):2497-504. https://doi.org/10.1016/j.jid.2017.07.834.

12. Geoghegan JA, Irvine AD, Foster TJ. Staphylococcus aureus and atopic dermatitis: a complex and evolving relationship. Trends Microbiol. 2018; 26(6):484-97. https://doi.org/10.1016/j.tim.2017.11.008.

13. Bjerre RD, Bandier J, Skov L, Engstrand L, Johansen JD. The role of the skin microbiome in atopic dermatitis: a systematic review. $\mathrm{Br} J$ Dermatol. 2017; 177(5):1272-8. https://doi.org/10.1111/bjd.15390.

14. Cau L, Williams MR, Butcher AM, et al. Staphylococcus epidermidis protease EcpA can be a deleterious component of the skin microbiome in atopic dermatitis. J Allergy Clin Immunol. 2020.

15. Yeung M, Balma-Mena A, Shear N, Simor A, Pope E, Walsh S, et al. Identification of major clonal complexes and toxin producing strains among Staphylococcus aureus associated with atopic dermatitis. Microbes Infect. 2011;13(2):189-97. https://doi.org/10.1016/j.micinf.2010.10.023.

16. Botha M, Basera W, Facey-Thomas HE, Gaunt B, Gray CL, Ramjith J, et al. Rural and urban food allergy prevalence from the south African food allergy (SAFFA) study. J Allergy Clin Immunol. 2019;143(2):662-8 e662. https://doi. org/10.1016/j.jaci.2018.07.023. 
17. Williams HC, Burney PG, Pembroke AC, Hay RJ. The U.K. working Party's diagnostic criteria for atopic dermatitis. III. Independent hospital validation. Br J Dermatol. 1994;131(3):406-16. https://doi.org/10.1111/j.1365-2133.1994. tb08532.x.

18. Oranje AP. Practical issues on interpretation of scoring atopic dermatitis: SCORAD index, objective SCORAD, patient-oriented SCORAD and three-item severity score. Curr Probl Dermatol. 2011;41:149-55. https://doi.org/10.1159/ 000323308.

19. Basera W, Botha M, Gray CL, Lunjani N, Watkins ASM, Venter C, et al. The south African food sensitisation and food allergy population-based study of IgE-mediated food allergy: validity, safety, and acceptability. Ann Allergy Asthma Immunol. 2015;115(2):113-9. https://doi.org/10.1016/j.anai.2015.06. 003.

20. Dube FS, Kaba M, Whittaker E, Zar HJ, Nicol MP. Detection of Streptococcus pneumoniae from different types of nasopharyngeal swabs in children. PLoS One. 2013;8(6):e68097. https://doi.org/10.1371/journal.pone.0068097.

21. Kateete DP, Kimani CN, Katabazi FA, Okeng A, Okee MS, Nanteza A, et al. Identification of Staphylococcus aureus: DNase and Mannitol salt agar improve the efficiency of the tube coagulase test. Ann Clin Microbiol Antimicrob. 2010;9(1):23. https://doi.org/10.1186/1476-0711-9-23.

22. Leung $\mathrm{MH}$, Oriyo NM, Gillespie $\mathrm{SH}$, Charalambous BM. The adaptive potential during nasopharyngeal colonisation of Streptococcus pneumoniae. Infect Genet Evol. 2011;11(8):1989-95. https://doi.org/10.1016/ j.meegid.2011.09.002.

23. Brakstad OG, Aasbakk K, Maeland JA. Detection of Staphylococcus aureus by polymerase chain reaction amplification of the nuc gene. J Clin Microbiol. 1992;30(7):1654-60. https://doi.org/10.1128/JCM.30.7.1654-1660.1992.

24. Koreen L, Ramaswamy SV, Graviss EA, Naidich S, Musser JM, Kreiswirth BN. Spa typing method for discriminating among Staphylococcus aureus isolates: implications for use of a single marker to detect genetic micro- and macrovariation. J Clin Microbiol. 2004;42(2):792-9. https://doi.org/10.1128/ JCM.42.2.792-799.2004.

25. Stegger M, Andersen PS, Kearns A, Pichon B, Holmes MA, Edwards G, et al. Rapid detection, differentiation and typing of methicillin-resistant Staphylococcus aureus harbouring either mecA or the new mecA homologue mecA (LGA251). Clin Microbiol Infect. 2012;18(4):395-400. https://doi.org/10.1111/j.1469-0691.2011.03715.x.

26. Votintseva AA, Fung R, Miller RR, Knox K, Godwin H, Wyllie DH, et al. Prevalence of Staphylococcus aureus protein a (spa) mutants in the community and hospitals in Oxfordshire. BMC Microbiol. 2014;14(1):63. https://doi.org/10.1186/1471-2180-14-63.

27. Shopsin B, Gomez M, Montgomery SO, Smith DH, Waddington M, Dodge $D E$, et al. Evaluation of protein a gene polymorphic region DNA sequencing for typing of Staphylococcus aureus strains. J Clin Microbiol. 1999;37(11): 3556-63. https://doi.org/10.1128/JCM.37.11.3556-3563.1999.

28. Mellmann A, Weniger T, Berssenbrugge $C$, et al. Based upon repeat pattern (BURP): an algorithm to characterize the long-term evolution of Staphylococcus aureus populations based on spa polymorphisms. BMC Microbiol. 2007;7(1):98. https://doi.org/10.1186/1471-2180-7-98.

29. Di Domenico EG, Cavallo I, Bordignon V, et al. Inflammatory cytokines and biofilm production sustain Staphylococcus aureus outgrowth and persistence: a pivotal interplay in the pathogenesis of atopic dermatitis. Sci Rep. 2018;8(1):9573. https://doi.org/10.1038/s41598-018-27421-1.

30. Tauber M, Balica S, Hsu CY, Jean-Decoster C, Lauze C, Redoules D, et al. Staphylococcus aureus density on lesional and nonlesional skin is strongly associated with disease severity in atopic dermatitis. J Allergy Clin Immunol. 2016;137(4):1272-4 e1273. https://doi.org/10.1016/j.jaci.2015.07.052.

31. Pascolini C, Sinagra J, Pecetta S, et al. Molecular and immunological characterization of Staphylococcus aureus in pediatric atopic dermatitis: implications for prophylaxis and clinical management. Clin Dev Immunol. 2011;2011:718708.

32. Wrobel J, Tomczak H, Jenerowicz D, Czarnecka-Operacz M. Skin and nasal vestibule colonisation by Staphylococcus aureus and its susceptibility to drugs in atopic dermatitis patients. Ann Agric Environ Med. 2018;25(2):3347. https://doi.org/10.26444/aaem/85589.

33. Bilal JA, Ahmad MI, Robaee AA, Alzolibani AA, Shobaili HA, Al-Khowailed MS. Pattern of bacterial colonization of atopic dermatitis in saudi children. J Clin Diagn Res. 2013;7(9):1968-70. https://doi.org/10.7860/JCDR/2013/5506.3371.

34. Clausen ML, Edslev SM, Andersen PS, Clemmensen K, Krogfelt KA, Agner T. Staphylococcus aureus colonization in atopic eczema and its association with filaggrin gene mutations. Br J Dermatol. 2017;177(5):1394-400. https:// doi.org/10.1111/bjd.15470.
35. Fard-Mousavi N, Mosayebi G, Amouzandeh-Nobaveh A, Japouni-Nejad A, Ghaznavi-Rad E. The dynamic of Staphylococcus aureus nasal carriage in Central Iran. Jundishapur J Microbiol. 2015;8(7):e20760. https://doi.org/10. 5812/jjm.20760v2.

36. Park HY, Kim CR, Huh IS, Jung MY, Seo EY, Park JH, et al. Staphylococcus aureus colonization in acute and chronic skin lesions of patients with atopic dermatitis. Ann Dermatol. 2013;25(4):410-6. https://doi.org/10.5021/ad.2 013.25.4.410.

37. Kong HH, Oh J, Deming C, Conlan S, Grice EA, Beatson MA, et al. Temporal shifts in the skin microbiome associated with disease flares and treatment in children with atopic dermatitis. Genome Res. 2012;22(5):850-9. https:// doi.org/10.1101/gr.131029.111.

38. Gupta VK, Paul S, Dutta C. Geography, Ethnicity or Subsistence-Specific Variations in Human Microbiome Composition and Diversity. Front Microbiol. 2017;8:1162

39. Cooper PJ, Amorim LD, Figueiredo CA, Esquivel R, Tupiza F, Erazo S, et al. Effects of environment on human cytokine responses during childhood in the tropics: role of urban versus rural residence. World Allergy Organ J. 2015;8(1):22. https://doi.org/10.1186/s40413-015-0071-2.

40. Sollid JU, Furberg AS, Hanssen AM, Johannessen M. Staphylococcus aureus: determinants of human carriage. Infect Genet Evol. 2014;21:531-41. https:// doi.org/10.1016/j.meegid.2013.03.020.

41. Andersen PS, Larsen LA, Fowler VG Jr, Stegger M, Skov RL, Christensen K. Risk factors for Staphylococcus aureus nasal colonization in Danish middleaged and elderly twins. Eur J Clin Microbiol Infect Dis. 2013;32(10):1321-6. https://doi.org/10.1007/s10096-013-1882-0.

42. Valacchi G, Sticozzi C, Pecorelli A, Cervellati F, Cervellati C, Maioli E. Cutaneous responses to environmental stressors. Ann N Y Acad Sci. 2012; 1271(1):75-81. https://doi.org/10.1111/j.1749-6632.2012.06724.x.

43. Addor FA, Takaoka R, Rivitti EA, Aoki V. Atopic dermatitis: correlation between non-damaged skin barrier function and disease activity. Int J Dermatol. 2012;51(6):672-6. https://doi.org/10.1111/j.1365-4632.2011.05176.x

44. Lam NL, Smith KR, Gauthier A, Bates MN. Kerosene: a review of household uses and their hazards in low- and middle-income countries. J Toxicol Environ Health B Crit Rev. 2012;15(6):396-432. https://doi.org/10.1080/1093 7404.2012.710134.

45. Wangchuk T, Mazaheri M, Clifford S, Dudzinska MR, He C, Buonanno G, et al. Children's personal exposure to air pollution in rural villages in Bhutan. Environ Res. 2015;140:691-8. https://doi.org/10.1016/j.envres.2015.06.006.

46. Puzzolo E, Zerriffi $H$, Carter $E$, Clemens $H$, Stokes $H$, Jagger $P$, et al. Supply considerations for scaling up clean cooking fuels for household energy in low- and middle-income countries. Geohealth. 2019;3(12):370-90. https:// doi.org/10.1029/2019GH000208.

47. Verkade E, Kluytmans J. Livestock-associated Staphylococcus aureus CC398: animal reservoirs and human infections. Infect Genet Evol. 2014;21:523-30. https://doi.org/10.1016/j.meegid.2013.02.013.

48. Campbell SJ, Deshmukh HS, Nelson CL, Bae IG, Stryjewski ME, Federspiel JJ, et al. Genotypic characteristics of Staphylococcus aureus isolates from a multinational trial of complicated skin and skin structure infections. J Clin Microbiol. 2008;46(2):678-84. https://doi.org/10.1128/JCM.01822-07.

49. Yu F, Liu Y, Lv J, Qi X, Lu C, Ding Y, et al. Antimicrobial susceptibility, virulence determinant carriage and molecular characteristics of Staphylococcus aureus isolates associated with skin and soft tissue infections. Braz J Infect Dis. 2015;19(6):614-22. https://doi.org/10.1016/j.bjid.2 015.08.006.

50. Rijnders MI, Deurenberg RH, Boumans ML, et al. Population structure of Staphylococcus aureus strains isolated from intensive care unit patients in the Netherlands over an 11-year period (1996 to 2006). J Clin Microbiol. 2009;47(12):4090-5. https://doi.org/10.1128/JCM.00820-09.

51. Benito D, Aspiroz C, Gilaberte Y, Sanmartín R, Hernández-Martin Á, Alonso $M$, et al. Genetic lineages and antimicrobial resistance genotypes in Staphylococcus aureus from children with atopic dermatitis: detection of clonal complexes CC1, CC97 and CC398. J Chemother. 2016;28(5):359-66. https://doi.org/10.1179/1973947815Y.0000000044.

52. Egyir B, Guardabassi L, Esson J, Nielsen SS, Newman MJ, Addo KK, et al. Insights into nasal carriage of Staphylococcus aureus in an urban and a rural community in Ghana. PLoS One. 2014;9(4):e96119. https://doi.org/10.13 71/journal.pone.0096119.

53. Kim DW, Park JY, Park KD, et al. Are there predominant strains and toxins of Staphylococcus aureus in atopic dermatitis patients? Genotypic characterization and toxin determination of S. aureus isolated in adolescent 
and adult patients with atopic dermatitis. J Dermatol. 2009;36(2):75-81. https://doi.org/10.1111/j.1346-8138.2009.00592.x.

54. Schaumburg F, Ngoa UA, Kosters $K$, et al. Virulence factors and genotypes of Staphylococcus aureus from infection and carriage in Gabon. Clin Microbiol Infect. 2011;17(10):1507-13. https://doi.org/10.1111/j.1469-0691.2 011.03534.x.

55. Li T, Lu H, Wang X, et al. Molecular characteristics of Staphylococcus aureus causing bovine mastitis between 2014 and 2015. Front Cell Infect Microbiol. 2017;7:127.

\section{Publisher's Note}

Springer Nature remains neutral with regard to jurisdictional claims in published maps and institutional affiliations.

Ready to submit your research? Choose BMC and benefit from:

- fast, convenient online submission

- thorough peer review by experienced researchers in your field

- rapid publication on acceptance

- support for research data, including large and complex data types

- gold Open Access which fosters wider collaboration and increased citations

- maximum visibility for your research: over $100 \mathrm{M}$ website views per year

At $\mathrm{BMC}$, research is always in progress.

Learn more biomedcentral.com/submissions 